\title{
Factors Associated with Depressive Symptoms in Patients with Chronic Low Back Pain
}

\author{
Jae Yong Ha, M.D., Eun Soo Kim, M.D., Hyo Jae Kim, M.D., Sang Jun Park, M.D. \\ Department of Rehabilitation Medicine, Seoul Medical Center, Seoul 131-130, Korea
}

\begin{abstract}
Objective To investigate depressive symptoms and their related factors in patients with chronic low back pain in Korea.

Method A cross-sectional study using data from the fourth Korea National Health and Nutrition Examination Survey (KNHANES IV) 2009 was undertaken. The sample consisted of 1,426 participants with chronic low back pain. Multifactorial regression analysis was used to identify the association between depressive symptoms and socioeconomic demographics and other chronic diseases.

Results Among the 371 (26.0\%) patients with depression, significant factors associated with depressive symptoms were female gender (odds ratio [OR], 2.691; 95\% confidence interval [CI], 1.724-4.199), medical aid beneficiary (OR, 1.371; 95\% CI, 1.039-1.810), a dependent group for activities of daily living (OR, 1.570; 95\% CI, 1.180-2.087), 'not good' in the perceived health category (OR, 2.309; 95\% CI, 1.730-3.081) and in a cancer group (OR, 1.803; 95\% CI, 1.051-3.093).

Conclusion This study provides the foundation for managing patients with chronic low back pain and depressive symptoms. Clinicians managing chronic low back pain should consider risk factors for depressive symptoms.
\end{abstract}

Key Words Chronic low back pain, Depression, NHANES

\section{INTRODUCTION}

Low back pain is a common disease, and it is observed at least once in $70-85 \%$ of the population during their lifetime. Low back pain is important due to progress in treating chronic pain, which decreases productivity and

Received July 13, 2011; Accepted August 23, 2011

Corresponding author: Jae Yong Ha

Department of Rehabilitation Medicine, Seoul Medical Center, 371-6, Sinnae-dong, Jungrang-gu, Seoul 131-130, Korea

Tel: +82-2-2276-8514, Fax: +82-2-2276-7486, E-mail: jaeyong.ha@gmail. com

(c) This is an open-access article distributed under the terms of the Creative Commons Attribution Non-Commercial License (http:// creativecommons.org/licenses/by-nc/3.0) which permits unrestricted noncommercial use, distribution, and reproduction in any medium, provided the original work is properly cited.

Copyright $\odot 2011$ by Korean Academy of Rehabilitation Medicine the financial burden globally. ${ }^{1-5}$

Several psychiatric disorders commonly accompany chronic low back pain, and the rate of depressive symptoms is $30-60 \%$ among patients. ${ }^{6-8}$ According to previous studies, a group of patients with chronic low back pain accompanied by depressive symptoms show significantly higher subjective pain, but no difference was found in the functional states or organic lesions when organic lesions, a subjective pain measure, and functioning and treatment progression were compared with a group of patients with general chronic low back pain. Improvements are minimal after rehabilitation. ${ }^{9}$ The degree of depressive symptoms at the initiation of treatment and during the treatment period are the biggest independent factor for pain intensity in 
patients. ${ }^{10}$ Accordingly, depressive symptoms as well as organic lesions in patients with chronic low back pain are very important for patient management. Therefore, factors associated with depressive symptoms need to be understood to consider treatment for chronic low back pain. However, socioeconomic and demographic approaches are rare in studies about depressive symptoms accompanying patients with chronic low back pain in Korea. Additionally, the subjects were limited in previous studies, so the results may have been biased in specific areas. Therefore, it is difficult to represent the general population in Korea. ${ }^{9,11,12}$

The aim of this study was to investigate depressive symptoms accompanied by chronic low back pain and their related factors using data from questions of the fourth Korea National Health and Nutrition Examination Survey (KNHANES IV) 2009, performed to sample households selected to represent the entire nation of Korea in 2009.

\section{MATERIALS AND METHODS}

\section{Subjects}

In the health survey of the third year (2009) of KNHANES IV, a patient with chronic low back pain was defined as "ill more than 3 months during the past year" for the items about low back pain among the 7,893 in the sample population over 19 years old. In total, 1,426 (18.1\%) subjects were finally selected.

\section{Methods}

The depressive symptom group was defined as those who answered "yes" to: "Have you felt sorrow or despair that has affected your daily life more than 2 weeks continuously during the past year?" Age was limited to those over 20 years old. Four groups were investigated, and their marital status was confirmed. Education level was divided into "less than elementary school", "less than middle school", "less than high school", and "more than university". Family income was classified into quartiles. Medical security was divided into "employee health insurance subscribers", "local health insurance subscribers", and "medical-aid beneficiaries". Smoking status was classified into "smoking", "not-smoking currently", and "not applicable". Drinking frequency was classified into "less than once per month", "1-4 times per month", and "more than twice per week". Perceived health was divided into "very good, good, average, bad, very bad" and, one group included "very good, good, average" and the other included "bad, very bad". For items about activities of daily living (ADL), only "I am not disrupted from daily activity." was defined as independent. Chronic diseases included stroke, hypertension, diabetes, ischemic heart disease, liver cirrhosis, arthritis, asthma, and chronic renal failure. The cancer group included patients who had at least one cancer among stomach, liver, lung, cervical, breast, colon, and other cancers. Each disease was defined as "yes" for "Did a doctor diagnose the disease?" so errors decreased due to the subjective judgment. Body mass index (BMI) was classified into underweight $(<18.5)$, normal weight (18.524.9), and obese (>25).

\section{Data analysis}

SPSS 15.0 version was used for the statistical analysis (SPSS Inc., Chicago, USA). A p-value less than 0.05 was considered significant. A cross-tabulation was used for the distributive analysis of each factor between the depressive symptom group and the general group. Distribution differences were examined with the chisquare test. Significant factors in the univariate analysis were used as variables to identify factors related to depressive symptoms in a multiple logistic regression. Model 1 was analyzed before correction of variables and Model 2 was analyzed after correction.

\section{RESULTS}

Socioeconomic and demographic features of the study subjects

The depressive symptom group included 371 subjects (26.0\%) among 1,426 patients with low back pain (Table 1). The test group was comprised of 400 males (28.1\%) and 1,026 females $(71.9 \%)$. In total, 124 subjects $(8.7 \%)$ were 20 -34 years old, 250 (17.5\%) were $35-49$ years, 387 (27.1\%) were 50-64 years, and $665(46.6 \%)$ were over 65 years. A total of 1,351 subjects $(94.7 \%)$ were married. A total of 793 subjects (55.6\%) had less than an elementary school education. For family income, 386 subjects $(27.2 \%)$ were in the first quartile, $375(26.4 \%)$ were in the second quartile, 339 (23.9\%) were in the third quartile, and $319(22.5 \%)$ were in the fourth quartile. There were 
Table 1. General Characteristics of the Study Subjects

\begin{tabular}{|c|c|c|}
\hline & Characteristics & $\begin{array}{c}\text { Total } \\
(\mathrm{N}=1,426)\end{array}$ \\
\hline & & No. (\%) \\
\hline Sex & Male & $400(28.1)$ \\
\hline & Female & $1,026(71.9)$ \\
\hline Age & $20-34$ & $124(8.7)$ \\
\hline & $35-49$ & $250(17.5)$ \\
\hline & $50-64$ & $387(27.1)$ \\
\hline & $65+$ & $665(46.6)$ \\
\hline Living with spouse & Single & $74(5.2)$ \\
\hline (missing=1) & Married & $1,351(94.7)$ \\
\hline Education & $\leq$ Elementary school & $793(55.6)$ \\
\hline & $\leq$ Middle school & $167(11.7)$ \\
\hline & $\leq$ High school & $324(22.7)$ \\
\hline & $\geq$ University & $142(10.0)$ \\
\hline Income (quartile) & 1st (lowest) & $386(27.2)$ \\
\hline (missing=7) & 2nd & $375(26.4)$ \\
\hline & 3rd & $339(23.9)$ \\
\hline & 4th (highest) & $319(22.5)$ \\
\hline Medical security & Medical Aid & $121(8.5)$ \\
\hline (missing=5) & National Health (local) & $462(32.5)$ \\
\hline & National Health & $838(59.0)$ \\
\hline & (Employee) & \\
\hline Perceived health & Good & $678(47.5)$ \\
\hline & Not good & $748(52.5)$ \\
\hline $\mathrm{ADL}$ (missing $=1$ ) & Independent & $780(54.7)$ \\
\hline & Dependent & $645(45.3)$ \\
\hline Number of & 0 & $650(45.6)$ \\
\hline chronic disease & 1 & $430(30.2)$ \\
\hline & 2 & $241(16.9)$ \\
\hline & $\geq 3$ & $105(7.4)$ \\
\hline Cancer & No & $1,359(95.3)$ \\
\hline & Yes & $67(4.7)$ \\
\hline BMI (missing=3) & Underweight & $55(3.9)$ \\
\hline & Normal weight & $858(60.3)$ \\
\hline & Obese & $510(35.8)$ \\
\hline Smoking status & Current smoker & $205(14.4)$ \\
\hline (missing=1) & Ex-smoker & $226(15.8)$ \\
\hline & Non-smoker & $994(69.8)$ \\
\hline Drinking & $<1$ time per month & $893(62.6)$ \\
\hline frequency & 1-4 times per month & $321(22.5)$ \\
\hline & $\geq 2$ times per week & $212(14.9)$ \\
\hline Depressive & No & $1,055(74.0)$ \\
\hline symptom & Yes & $371(26.0)$ \\
\hline
\end{tabular}

ADL: Activities of daily living, BMI: Body mass index, Chronic disease: Stroke, hypertension, diabetes, ischemic heart disease, liver cirrhosis, arthritis, asthma, and chronic renal failure, Cancer: Stomach, liver, lung, cervical, breast, colon, and other cancers
838 (59.0\%) employee health-insurance subscribers 462 (32.5\%) local health-insurance subscribers, and 121 (8.5\%) medical-aid beneficiaries. For perceived health, 748 subjects (52.5) were "not good" and 780 subjects (54.7\%) were independent with their ADL. A total of 650 subjects (45.6\%) showed no accompanying disease, 430 (30.2\%) showed one, 241 (16.9\%) showed two, and 105 (7.4\%) showed more than three diseases. The cancer group contained 67 subjects (4.7\%). In total, 510 subjects (35.8\%) were obese, 858 (60.3\%) were normal weight, and $55(3.9 \%)$ were underweight. For smoking status, 205 subjects (14.4\%) were current smokers, 226 (15.8\%) quit smoking, and 994 (69.7\%) were non-smokers. For drinking frequency, 893 subjects $(62.6 \%)$ drank less than once per month, 321 (22.5\%) drank 1-4 times per month, and $212(14.9 \%)$ drank more than twice per week.

\section{Comparison of characteristics ac cording to depressive symptoms}

Depressive symptoms were significantly higher in females $(\mathrm{p}<0.001)$ (Table 2). Depressive symptoms were higher as education level $(p=0.003)$ and family income ( $\mathrm{p}=0.001)$ decreased, and higher in medicalaid beneficiaries $(p<0.001)$ than in health insurance subscribers. Depressive symptoms were significantly higher in the "not good" group of perceived health $(\mathrm{p}<0.001)$ and in the ADL "dependent" group ( $\mathrm{p}<0.001)$. Cancer $(p=0.010)$, stroke $(p=0.042)$, myocardial infarction or angina pectoris $(\mathrm{p}=0.009)$, and arthritis $(\mathrm{p}=0.007)$ showed significant results for relevance to accompanying chronic diseases, and more depressive symptoms were observed as the number of chronic diseases increased $(\mathrm{p}=0.018)$. The underweight group tended to show more depressive symptoms than the normal or overweight groups, but it was not statistically significant. Depressive symptoms were significant higher in the ex-smoker and non-smoker groups than those in the current smoker group ( $\mathrm{p}=0.006$ ). Depressive symptoms were significantly higher in the groups who drank alcohol "less than once per month" and " 1 to 4 times per month" than those who drank "more than twice per week" $(p=0.026)$.

\section{Predictable factors for depressive symptoms}

In the Model 1 analysis, females showed more depressive symptoms than males (OR, 2.465; 95\% CI, 1.817-3.344), and the second (OR, 1.480; 95\% CI, 1.038-2.109) and first 
Table 2. Sociodemographic and Medical Factors Influencing Depressive Symptom in Patients with Chronic Low Back Pain

\begin{tabular}{|c|c|c|c|c|}
\hline & & Depress & mptom & n nolu \\
\hline & & No & Yes & p-value \\
\hline Sex & Male & $340(85.0)$ & $60(15.0)$ & .000 \\
\hline & Female & $715(69.7)$ & $311(30.3)$ & \\
\hline Age & $20-34$ & $93(75.0)$ & $31(25.0)$ & .337 \\
\hline & $35-49$ & $196(78.4)$ & $54(21.6)$ & \\
\hline & $50-64$ & $283(73.1)$ & $104(26.9)$ & \\
\hline & $65+$ & $483(72.6)$ & $182(27.4)$ & \\
\hline Living with spouse & Single & $56(75.7)$ & $18(24.3)$ & .790 \\
\hline & Married & $998(73.9)$ & $353(26.1)$ & \\
\hline Education & $\leq$ Elementary school & $557(70.2)$ & $236(29.8)$ & .003 \\
\hline & $\leq$ Middle school & $130(77.8)$ & $37(22.2)$ & \\
\hline & $\leq$ High school & $252(77.8)$ & $72(22.2)$ & \\
\hline & $\geq$ University & $116(81.7)$ & $26(18.3)$ & \\
\hline Income & 1st (lowest) & $267(69.2)$ & $119(30.8)$ & .001 \\
\hline & 2nd & $272(72.5)$ & $103(27.5)$ & \\
\hline & 3rd & $257(75.8)$ & $82(24.2)$ & \\
\hline & 4th (highest) & $254(79.6)$ & $65(20.4)$ & \\
\hline Medical security & Medical Aid & $72(59.5)$ & $49(40.5)$ & .000 \\
\hline & National Health (local) & $335(72.5)$ & $127(27.5)$ & \\
\hline & National Health (employee) & $647(77.2)$ & $191(22.8)$ & \\
\hline Perceived health & Good & $570(84.1)$ & $108(15.9)$ & .000 \\
\hline & Not good & $485(64.8)$ & $263(35.2)$ & \\
\hline ADL & Independent & $630(80.8)$ & $150(19.2)$ & .000 \\
\hline & Dependent & $424(65.7)$ & $221(34.3)$ & \\
\hline Number of chronic disease & 0 & $500(76.9)$ & $150(23.1)$ & .018 \\
\hline & 1 & $318(74.0)$ & $112(26.0)$ & \\
\hline & 2 & $170(70.5)$ & $71(29.5)$ & \\
\hline & $\geq 3$ & $67(63.8)$ & $38(36.2)$ & \\
\hline Cancer & No & $1,015(74.7)$ & $344(25.3)$ & .010 \\
\hline & Yes & $40(59.7)$ & $27(40.3)$ & \\
\hline BMI & Underweight & $39(70.9)$ & $16(29.1)$ & .165 \\
\hline & Normal weight & $621(72.4)$ & $237(27.6)$ & \\
\hline & Obese & $392(76.9)$ & $118(23.1)$ & \\
\hline Stroke & No & $1,021(74.5)$ & $350(25.5)$ & .042 \\
\hline & Yes & $34(61.8)$ & $21(38.2)$ & \\
\hline Hypertension & No & $708(74.4)$ & $244(25.6)$ & .654 \\
\hline & Yes & $347(73.2)$ & $127(26.8)$ & \\
\hline Diabetes & No & $932(74.2)$ & $324(25.8)$ & .641 \\
\hline & Yes & $123(72.4)$ & $47(27.6)$ & \\
\hline IHD & No & $1,033(74.5)$ & $353(25.5)$ & .009 \\
\hline & Yes & $22(55.0)$ & $18(45.0)$ & \\
\hline
\end{tabular}


Table 2. Continued

\begin{tabular}{|c|c|c|c|c|}
\hline & & \multicolumn{2}{|c|}{ Depressive symptom } & \multirow{2}{*}{ p-value } \\
\hline & & No & Yes & \\
\hline \multirow[t]{2}{*}{ Liver cirrhosis } & No & $1,051(74.0)$ & $370(26.0)$ & \multirow{2}{*}{.999} \\
\hline & Yes & $4(80.0)$ & $1(20.0)$ & \\
\hline \multirow[t]{2}{*}{ Arthritis } & No & $759(76.1)$ & $239(23.9)$ & \multirow{2}{*}{.007} \\
\hline & Yes & $296(69.2)$ & $132(30.8)$ & \\
\hline \multirow[t]{2}{*}{ Asthma } & No & $1,010(74.5)$ & $345(25.5)$ & \multirow{2}{*}{.051} \\
\hline & Yes & $45(63.4)$ & $26(36.6)$ & \\
\hline \multirow[t]{2}{*}{$\mathrm{CRF}$} & No & $1,051(73.9)$ & $371(26.1)$ & \multirow{2}{*}{.578} \\
\hline & Yes & $4(100)$ & $0(0)$ & \\
\hline \multirow[t]{3}{*}{ Smoking status } & Current smoker & $167(81.5)$ & $38(18.5)$ & \multirow{3}{*}{.006} \\
\hline & Ex-smoker & $178(78.8)$ & $48(21.2)$ & \\
\hline & Non-smoker & $709(71.3)$ & $285(28.7)$ & \\
\hline \multirow[t]{3}{*}{ Drinking frequency } & $<1$ time per month & $642(71.9)$ & $251(28.1)$ & \multirow{3}{*}{.026} \\
\hline & 1-4 times per month & $242(75.4)$ & $79(24.6)$ & \\
\hline & $\geq 2$ times per week & $171(80.7)$ & $41(19.3)$ & \\
\hline
\end{tabular}

ADL:Activities of daily living, BMI: Body mass index, IHD: Ischemic heart disease, CRF: Chronic renal failure, Chronic diseases: Stroke, hypertension, diabetes, ischemic heart disease, liver cirrhosis, arthritis, asthma, and chronic renal failure, Cancer: Stomach, liver, lung, cervical, breast, colon, and other cancers

quartile (OR,1.742; 95\% CI, 1.230-2.466) showed more depressive symptoms than the fourth quartile of family income. More depressive symptoms were shown for subjects with "less than an elementary school" education (OR, 1.890; 95\% CI, 1.203-2.970) than those with "more than university", and medical aid beneficiaries (OR, 2.305; 95\% CI, 1.550-3.430) showed more depressive symptoms than those of employee health insurance subscribers (Table 3). The dependent group in ADL (OR, 2.189; 95\% CI, 1.720-2.786) showed more depressive symptoms than those of the independent group. "Not good" in perceived health (OR, 2.862; 95\% CI, 2.219-3.692) resulted in more depressive symptoms than those of the "good" group. Depressive symptoms were significantly higher for patients with cancer (OR, 1.992; 95\% CI, 1.204-3.294), stroke (OR, 1.802; 95\% CI, 1.032-3.146), myocardial infarction or angina pectoris (OR, 2.394;, 95\% CI, 1.2694.516), and arthritis (OR, 1.416; 95\% CI, 1.101-1.821). The group with more than three accompanying chronic diseases (OR, 2.097; 95\% CI, 1.317-3.340), and past (OR, 2.038; 95\% CI, 1.440-2.883) and present (OR, 1.719; 95\% CI, 1.178-2.510) smokers had more depressive symptoms than the non-smoker group. However females (OR, 2.691; 95\% CI, 1.724-4.199), medical-aid beneficiaries
(OR,1.371; 95\% CI, 1.039-1.810), the ADL dependent group (OR, 1.570; 95\% CI, 1.180-2.087), 'not good:' for perceived health (OR, 2.309; 95\% CI, 1.730-3.081) and the cancer group (OR, 1.803; 95\% CI, 1.051-3.093) were the only statistically significant variables in the multivariate regression after the correction.

\section{DISCUSSION}

Socioeconomic and demographic factors related to depressive symptoms in patients with chronic low back pain were studied based on the KNHANES IV (2009). Gender, medical security, ADL, perceived health and accompanied cancers were related to depressive symptoms after correcting for other variables.

Generally, the interrelationship between gender and depressive symptoms are well known. The prevalence rate in suspected patients with depression who scored more than 16 points on the Center for Epidemiological Studies-Depression Scale in Korea was $23.1 \%$ in males and $27.4 \%$ in females. In severe cases of depression ( $>25$ points), the prevalence rate was $6.8 \%$ in males and $10.4 \%$ in females. ${ }^{13}$ According to the type of medical security, depressive symptoms were significantly higher in medi- 
Table 3. Risk Factors for Depressive Symptoms in Patients with Chronic Low Back Pain: Adjusted Odds Ratio from a Multivariate Logistic Regression Model

\begin{tabular}{|c|c|c|c|c|c|}
\hline \multicolumn{2}{|c|}{ Factors } & \multirow{2}{*}{$\begin{array}{c}\begin{array}{c}\text { Odds ratio } \\
\text { model 1* }\end{array} \\
2.465\end{array}$} & \multirow{2}{*}{$\begin{array}{c}95 \% \mathrm{CI} \\
1.817-3.344\end{array}$} & \multirow{2}{*}{$\begin{array}{c}\begin{array}{c}\text { Odds ratio } \\
\text { model }^{\dagger}\end{array} \\
2.691\end{array}$} & \multirow{2}{*}{$\begin{array}{c}\mathbf{9 5 \%} \text { CI } \\
1.724-4.199\end{array}$} \\
\hline Sex (ref=male) & Female & & & & \\
\hline \multirow[t]{3}{*}{ Income (ref $=4$ th (highest)) } & 3rd & 1.247 & $0.862-1.803$ & 1.404 & $0.961-2.053$ \\
\hline & 2nd & 1.480 & $1.038-2.109$ & 1.302 & $0.891-1.902$ \\
\hline & 1st (lowest) & 1.742 & $1.230-2.466$ & 1.049 & $0.710-1.549$ \\
\hline \multirow[t]{3}{*}{ Education (ref $\geq$ University) } & $\leq$ Elementary school & 1.890 & $1.203-2.970$ & 1.120 & $0.669-1.875$ \\
\hline & $\leq$ Middle school & 1.270 & $0.725-2.224$ & 1.096 & $0.596-2.013$ \\
\hline & $\leq$ High school & 1.275 & $0.774-2.101$ & 1.309 & $0.764-2.242$ \\
\hline \multirow[t]{2}{*}{ Medical security (ref=employee) } & Local & 1.284 & $0.990-1.666$ & 0.818 & $0.515-1.297$ \\
\hline & Medical aid & 2.305 & $1.550-3.430$ & 1.371 & $1.039-1.810$ \\
\hline ADL (ref=independent) & Dependent & 2.189 & $1.720-2.786$ & 1.570 & $1.180-2.087$ \\
\hline Perceived health (ref=good) & Not good & 2.862 & 2.219-3.692 & 2.309 & $1.730-3.081$ \\
\hline Cancer (ref=No) & Yes & 1.992 & $1,204-3.294$ & 1.803 & $1.051-3.093$ \\
\hline Stroke (ref=No) & Yes & 1.802 & $1.032-3.146$ & 1.281 & $0.673-2.439$ \\
\hline IHD (ref=No) & Yes & 2.394 & $1.269-4.516$ & 1.987 & $0.980-4.025$ \\
\hline Arthritis (ref=No) & Yes & 1.416 & $1.101-1.821$ & 0.967 & $0.680-1.374$ \\
\hline \multirow[t]{3}{*}{ Chronic disease (ref=0) } & 1 & 1.173 & $0.886-1.553$ & 0.970 & $0.554-1.701$ \\
\hline & 2 & 1.391 & $1.000-1.936$ & 1.001 & $0.569-1.761$ \\
\hline & $\geq 3$ & 2.097 & $1.317-3.340$ & 1.092 & $0.587-2.030$ \\
\hline \multirow[t]{2}{*}{ Smoking (ref=Non-smoker) } & Current smoker & 1.719 & $1.178-2.510$ & 0.847 & $0.523-1.372$ \\
\hline & Ex-smoker & 2.038 & $1.440-2.883$ & 1.160 & $0.722-1.864$ \\
\hline Drinking frequency & 1-4 times per month & 1.198 & $0.894-1.605$ & 1.095 & $0.718-1.669$ \\
\hline (ref $=<1$ time per month) & $\geq 2$ times per week & 0.734 & $0.480-1.123$ & 1.154 & $0.836-1.593$ \\
\hline
\end{tabular}

Chronic diseases: Stroke, hypertension, diabetes, ischemic heart disease, liver cirrhosis, arthritis, asthma, and chronic renal failure

${ }^{*}$ Model 1: Crude odds ratio, ${ }^{\dagger}$ Model 2: Adjustment was performed

cal-aid beneficiaries than those in employee health insurance subscribers. In medical-aid beneficiaries, low level of education, single patients who lived alone, and low monthly average family income were considered in previous studies and selection standards were referred, so there might be indirect effects. ${ }^{14}$ Depressive symptoms increased in the low-ability ADL group compared to those in the high-ability group, which was similar to a previous study. ${ }^{15}$ Depressive symptoms increased as perceived health became poorer, and the reason is associated with studies about health-related quality of life and depressive symptoms. ${ }^{16}$ The correlation between accompanied cancers and depressive symptoms has been revealed in many studies. In particular, patients with pancreatic cancer, oropharyngeal cancer, and breast cancer show more depressive symptoms and the prevalence rates are 20$25 \%$. $^{17-20}$

Many studies have reported the relationship between depressive symptoms and chronic diseases. In this study, stroke, myocardial infarction or angina pectoris, and arthritis were significantly different in the univariate analysis. In previous studies of stroke, depressive symptoms were different by location of the lesion, and more depressive symptoms were observed when the lesion was located on the left side. ${ }^{21,22}$ In previous studies about myocardial infarction or angina pectoris, many patients showed depressive symptoms and high morbidity rates, and the male result was similar to that of females, so our results agreed with those of previous studies. ${ }^{23,24}$ In addition, depression and severity of de- 
pression symptoms influences a decrease in arthritis symptoms. ${ }^{25,26}$ In the univariate analysis, depressive symptoms increased as the number of chronic diseases increased. Thus, by contracting more chronic diseases, related physical symptoms would increase and functional disorders would occur, which would increase medical expenses. Therefore, increasing depressive symptoms were expected. ${ }^{27}$

In the univariate analysis results about smoking and depressive symptoms, the past and present smoker groups showed fewer depressive symptoms than those in the non-smoker group. According to previous studies, depressive symptoms increase remarkably when a smoker group was forbidden to smoke. However, smoking has generally been reported to increase depressive symptoms, so it is difficult to say that smoking has a positive effect on depressive symptoms. ${ }^{28-31}$ The group who drank alcohol "less than once per month" showed more depressive symptoms than those who drank "more than twice per week" and this result was also different from previous studies. ${ }^{32,33}$ This difference might have been caused by the plurality of females who showed less smoking and drinking rates among participants in this study.

The first limitation of this study is that it was cross-sectional, so it was difficult to interpret chronic low back pain and depressive symptoms as a simple cause and effect relationship. In general, chronic low back pain occurred first and then depressive symptoms followed but several factors related to depressive symptoms could also cause depressive symptoms, so previous studies have indicated careful interpretation of these types of data. ${ }^{34}$ Questions about the intensity of low back pain were not used for patients with chronic low back pain, so depressive symptoms and the differences with ADL were not compared. In addition, a single question was provided to measure the degree of depression instead of established selection tools, so accuracy could be limited. However, the one question of "Do you often feel sad or depressed?" showed a sensitivity of $86 \%$, a specificity of $78 \%$, and positive predictive and negative predictive values of $82 \%$ in previous studies, so the error was thought to be small. ${ }^{35}$ A self-writing method was used for the health survey, so accuracy could be limited. However, the survey was performed at a mobile clinic center with an investigator, so it was different with other methods without an observer.

Despite these limitations, this study included every family in Korea so the results are representative, because it was not limited to specific hospitals or local areas. Relatively more patients with chronic low back pain were investigated compared to previous studies. Additionally, psychosocial risk factors as well as organic disturbances could be evaluated through socioeconomic and demographic approaches regarding factors related to patients with chronic low back pain and depressive symptoms. Therefore, this study suggests various ways to approach patients with low back pain.

\section{CONCLUSION}

Low back pain is observed at least once in most people's lives and has a significant effect on society as well as each patient because it is chronic. In particular, psychological factors as well as organic disturbances act in a complex manner for a prognosis. Therefore, a diagnosis of depressive symptoms in patients with chronic low back pain and an analysis of related factors are essential for comprehensive rehabilitation.

Socioeconomic and demographic factors related to depressive symptoms were studied by KNHANES in patients who reported chronic low back pain more than 3 months during the past year. This result suggests preliminary data to grasp factors influencing depressive symptoms. Thus, more effects are expected when managing chronic low back pain by combining organic disturbance, which causes pain, and the emotional aspects during treatment.

\section{REFERENCES}

1. Andersson GB. Epidemiological features of chronic low-back pain. Lancet 1999; 354: 581-585

2. Frank A. Low back pain. BMJ 1993; 306: 901-909

3. Volinn E, Van Koevering D, Loeser JD. Back sprain in industry. The role of socioeconomic factors in chronicity. Spine (Phila Pa 1976) 1991; 16: 542-548

4. Webster BS, Snook SH. The cost of 1989 workers' compensation low back pain claims. Spine (Phila $\mathrm{Pa}$ 1976) 1994; 19: 1111-1115

5. Kim HS, Choi JW, Chang SH, Lee KS, Oh JY. Treatment duration and cost of work-related low back pain in Korea. J Korean Med Sci 2005; 20: 127-131 
6. Reme SE, Tangen T, Moe T, Eriksen HR. Prevalence of psychiatric disorders in sick listed chronic low back pain patients. Eur J Pain 2011: [Epub ahead of print]

7. Bair MJ, Robinson RL, Katon W, Kroenke K. Depression and pain comorbidity: a literature review. Arch Intern Med 2003; 163: 2433-2345

8. Gallagher RM, Verma S. Managing pain and comorbid depression: a public health challenge. Semin Clin Neuropsychiatry 1999; 4: 203-220

9. Seok H, Son BK, Ha YR, Ryu HH, Moon JH. Clinical influence of emotional depression on chronic low back pain. J Korean Acad Rehab Med 2003; 27: 568574

10. Williams LS, Jones WJ, Shen J, Robinson RL, Weinberger M, Kroenke K. Prevalence and impact of depression and pain in neurology outpatients. J Neurol Neurosurg Psychiatry 2003; 74: 1587-1589

11. Sohn MK, Chae JM, Yune SH. Pain and psychometric characteristics related to disability evaluation in patients with chronic low back pain. J Korean Acad Rehab Med 2000; 24: 125-131

12. Yoo TW, Kang SW, Moon JH. Change in epidemiologic characteristics of the patients with neck and back pain. J Korean Acad Rehab Med 2004; 28: 579-585

13. Cho MJ, Nam JJ, Suh GH. Prevalence of symptoms of depression in a nationwide sample of Korean adults. Psychiatry Res 1998; 81: 341-352

14. Rhee CW. Health status and self-management barriers in people with diabetes: a comparison by Medicaid beneficiary status. Korean Journal of Social Welfare 2008; 60: 231-251

15. Rush AJ, Polatin P, Gatchel RJ. Depression and chronic low back pain: establishing priorities in treatment. Spine (Phila Pa 1976) 2000; 25: 2566-2571

16. Papakostas GI, Petersen T, Mahal Y, Mischoulon D, Nierenberg AA, Fava M. Quality of life assessments in major depressive disorder: a review of the literature. Gen Hosp Psychiatry 2004; 26: 13-17

17. Raison CL, Miller AH. Depression in cancer: new developments regarding diagnosis and treatment. Biol Psychiatry 2003; 54: 283-294

18. Evans DL, McCartney CF, Nemeroff CB, Raft D, Quade D, Golden RN, Haqqerty JJ Jr, Holmes V, Simon JS, Droba M, et al. Depression in women treated for gynecological cancer: clinical and neuroendocrine assessment. Am J Psychiatry 1986; 143: 447-452
19. McDaniel JS, Musselman DL, Porter MR, Reed DA, Nemeroff CB. Depression in patients with cancer. Diagnosis, biology, and treatment. Arch Gen Psychiatry 1995; 52: 89-99

20. Newport DJ, Nemeroff CB. Assessment and treatment of depression in the cancer patient. J Psychosom Res 1998; 45: 215-237

21. Narushima K, Kosier JT, Robinson RG. A reappraisal of poststroke depression, intra- and inter-hemispheric lesion location using meta-analysis. J Neuropsychiatry Clin Neurosci 2003; 15: 422-430

22. Robinson RG. Post-stroke depression: prevalence, diagnosis, treatment and disease progression. Biol Psychiatry 2003; 54: 376-387

23. Frasure-Smith N, Lesperance F, Juneau M, Talajic M, Bourassa MG. Gender, depression and one-year prognosis after myocardial infarction. Psychosom Med 1999; 61: 26-37

24. Carney RM, Freedland KE, Smith L, Lustman PJ, Jaffe AS. Relation of depression and mortality after myocardial infarction in women. Circulation 1991; 84: 1876-1877

25. Somers TJ, Keefe FJ, Godiwala N, Hoyler GH. Psychosocial factors and the pain experience of osteoarthritis patients: new findings and new directions. Curr Opin Rheumatol 2009; 21: 501-506

26. Isik A, Koca SS, Ozturk A, Mermi O. Anxiety and depression in patients with rheumatoid arthritis. Clin Rheumatol 2007; 26: 872-878

27. Katon WJ. Epidemiology and treatment of depression in patients with chronic medical illness. Dialoques Clin Neurosci 2011; 13: 7-23

28. Glassman AH, Covey LS, Stetner F, Rivelli S. Smoking cessation and the course of major depression: a follow-up study. Lancet 2001; 357: 1929-1932

29. Boden JM, Ferqusson DM, Horwood LJ. Cigarette smoking and depression: tests of causal linkages using a longitudinal birth cohort. Br J Psychiatry 2010; 196: 440-446

30. Munafo MR, Araya R. Cigarette smoking and depression: a question of causation. Br J Psychiatry 2010; 196: 425-426

31. Torres LD, Barrera AZ, Delucchi K, Penila C, PerezStable EJ, Munoz RF. Quitting smoking does not increase the risk of major depressive episodes among users of internet smoking cessation interventions. 
Psychol Med 2010; 40: 441-449

32. Petty F. The depressed alcoholic. Clinical features and medical management. Gen Hosp Psychiatry 1992; 14: 458-464

33. O'Sullivan K. Depression and its treatment in alcoholics: a review. Can J Psychiatry 1984; 29: 379-384

34. Fishbain DA, Cutler R, Rosomoff HL. Chronic pain- associated depression: antecedent or consequence of chronic pain? A review. Clin J Pain 1997; 13: 116-137

35. Watkins C, Daniels L, Jack C, Dickinson H, van Den Broek M. Accuracy of a single question in screening for depression in a cohort of patients after stroke: comparative study. BMJ 2001; 17: 1159 